\title{
Article
}

\section{Optimization of a $\mathrm{H}_{2}$ Liquefaction Pre-Cooling Process \& Esti- mate of Liquefaction Performance with Varying Ambient Tem- perature}

\author{
Steven Jackson 1,* and Eivind Brodal ${ }^{1}$ \\ 1 UiT-Norges Arktiske Universitetet \\ * Correspondence: steve.jackson@uit.no
}

\begin{abstract}
Hydrogen used as an energy carrier can provide an important route to the decarbonization of energy supplies. However, realizing this opportunity requires a significant increase in both production and transportation capacity. Part of the increase in transportation capacity could be provided by the shipping of liquid hydrogen, but this introduces an energy-intensive liquefaction step into the supply-chain. The energy required for liquefaction can be reduced by developing improved process designs, but since all low-temperature processes are affected by the available heat-sink temperature, local ambient conditions will also affect the energy penalty. This work studies how the energy consumption associated with liquefaction varies with heat-sink temperature through the optimization of design parameters for a typical next-generation hydrogen liquefaction process. The results show that energy consumption increases by around $20 \%$, across the cooling temperature range 5 to $50^{\circ} \mathrm{C}$. Considering just the range 20 to $30^{\circ} \mathrm{C}$ there is a $5 \%$ increase, illustrating the significant impact ambient temperature can have on energy consumption.
\end{abstract}

Keywords: hydrogen; liquefaction; optimization; ambient temperature

\section{Introduction}

Hydrogen used as an energy carrier, or used directly as a fuel, can provide an important route to the decarbonization of energy supplies through the replacement of fossil fuels like natural gas. Recent studies have even made the case that achieving a transition to carbon-free energy in the EU is impossible without a large increase in hydrogen production [1], and energy system modeling has found that "hydrogen and synfuels add up to between $20 \%$ and $50 \%$ of [EU] energy demand in transport in 2050" [2]. This positive view of the role that hydrogen could play in future low-carbon development is also reflected in political intent via the EU hydrogen strategy [3].

Reflecting this political support, research related to hydrogen energy has increased over recent years [4] with important topics including energy demand and supply modelling, the development of new and improved production technologies (e.g., novel integration of nuclear or renewable energy such as solar power [5]), and the development of new and improved applications for hydrogen energy (e.g., fuel cell development, steel manufacturing).

In all envisaged future hydrogen-based economies a significant increase in the transportation capacity for hydrogen is required. Although it is possible to transport hydrogen in trucks, either a compressed gas or a liquid at low temperature, in pipelines as a gas, or in ships as a liquid at low temperature, the optimum transportation strategy will depend on both the transportation capacity and the distance [6]. When the distance is significant it is reasonable to expect that shipping of hydrogen will be favored, and while researchers such as Ishimoto, et al. [7] have studied the economics of shipping liquefied hydrogen, some commercial steps have also been made, with the world's first liquid hydrogen carrier ship launched in Japan in 2019 [8]. 
If hydrogen is transported at large-scale as a liquid, a key part of the supply chain will be the liquefaction process, which is very energy intensive. The specific energy consumption (SEC) of the most efficient currently operating large-scale hydrogen liquefaction (LHL) plants lies in the range 13-15 kWh/kg [9], which is much higher that even the most efficient LNG processes, which have a SEC of around $240 \mathrm{kWh} /$ tonne. Because of this, there is significant interest in the development of new and improved LHL technologies that can help reduced SEC.

Research topics relating to improved LHL include the integration of renewable energy sources, such as solar energy [10] and geothermal energy [11]; the use of mixed refrigerants (MR) for pre-cooling [12-14]; and the use of helium in the cryogenic cooling and liquefaction part of the process $[15,16]$. Other research has focused on the impact of the conversion of ortho-hydrogen to para-hydrogen on the liquefaction process $[17,18]$ and the relative performance of different exchanger types $[13,18,19]$. The suggested efficiency of proposed concepts for LHL lie in the range $5-8 \mathrm{kWh} / \mathrm{kg}$ [9], which represents a substantial motivation for the implementation of these technologies in the next generation of LHL plants.

Although there exists a broad base of research into the performance of LHL processes no references were found to articles that study the impact of ambient temperature on the performance of the liquefaction process. The explanation for this is probably that the impact of cooling utility temperature on liquefaction process design is relatively small since the bulk of the process operates well below ambient temperature. However, results from earlier related study work have shown that the impact of ambient temperature on LNG liquefaction process can be significant, and has a material impact on the optimum MR composition used in the pre-cooling stage of this process [20]. Furthermore, the cumulative impact of ambient temperature on low-carbon energy supply chains where hydrogen liquefaction forms a part is of a more general interest. The aim of this work is, therefore, to study how the temperature of the available heat sink impacts the efficiency of the hydrogen liquefaction process.

\section{Materials and Methods}

\subsection{Selection of the Modeling Basis}

Although only a handful different types of liquefaction process are used in current operating LHL plants, a wide range of improved processes have been proposed. In the present study a comprehensive review of the various improved liquefaction technologies is outside the scope of work. Instead, a single, representative, improved process was selected to be used as the basis for the present study. The details of the selection process are described below.

Because the results from this study are intended to support further research in future low-carbon energy supply and, specifically, how different supply chain configurations affect efficiency, the improved concepts of most relevance are those technologies likely to be used in the near future. Taking the techno-economic analysis of Cardella et al. [21] as a basis, the improved technology that fits best with the aim of the study is the use of a mixed refrigerant $(\mathrm{MR})$ for pre-cooling of the hydrogen feed stream.

Most current, any many improved, hydrogen liquefaction processes are based on the division of the overall process into two parts: a pre-cooling step and a cryogenic-cooling step. In conventional LHL plant designs, the pre-cooling stage often uses liquid nitrogen (LIN) as a refrigerant, whereas the cryogenic-cooling step uses either helium in a Brayton cycle, or hydrogen in a Claude cycle [14]. In the cryogenic step, the hydrogen feed is generally cooled from below around $-90{ }^{\circ} \mathrm{C}$ to the final liquefaction temperature. Although the break-point temperature between the pre-cooling and the cryogenic step, $T_{\mathrm{p}}$, is potentially an optimization variable, the present study assumes that the impact of ambient temperature on operating parameters in the cryogenic step is small and, therefore, that $T_{\mathrm{p}}$ can be fixed. 
Typical of the concepts for improved energy consumption using MRs is the process studied in the work of Skaugen, et al. [13], which is based on a Claude cycle in cryogeniccooling step and a MR in the pre-cooling step. In this process the pre-cooling step and the portion of the cryogenic step that operates above $T_{\mathrm{p}}$ are not integrated. This allows the present study to consider the optimization of the pre-cooling process independently from the operation of the cryogenic-cooling process. In addition, because the details of the composition and operating conditions for the proposed MR cycle are clearly set-out in the work of Skaugen et al. [13], the present study uses the work of Skaugen as the basis for model development and validation.

Although the operating parameters in the cryogenic-cooling step are assumed fixed in the present study (i.e., they are not affected by ambient temperature), the energy consumption of the cryogenic-cooling cycle compressor is still affected by the exit temperature that the inter and after-coolers, $T_{\mathrm{c}}$, are designed to operate with, which would normally be set relative to the ambient temperature of the seawater, or air, used as the heatsink. Because of this, modelling of the performance of the cryogenic cycle compressor as it varies with $T_{\mathrm{c}}$ does form part of the present study.

Another important factor in the design and optimization of hydrogen liquefaction processes is the conversion of ortho to para hydrogen. This process releases a significant quantity of heat, affecting both the process design and the selection of optimum operating parameters. The conversion of the ortho isomer during liquefaction is typically promoted using a catalyst. The effectiveness of the catalyst and the residence time in the exchangers affects the approach to the equilibrium concentration and, subsequently, the temperature profile in the exchangers. However, across the range of $T_{\mathrm{c}}$ considered in this study, the equilibrium concentration of para-hydrogen does not vary significantly [9] and because both the outlet temperature for the pre-cooling process and the pre-cooling exchanger design are fixed in this study, the outlet ortho-para conversion ratio should also remain fixed, given a fixed conversion in the pre-cooling stage. Therefore, in the relative study of the impact of ambient temperature on pre-cooling process performance the conversion of ortho to para hydrogen is set outside the scope of the present study.

\subsection{Process Model Development}

As described above, the process model used in this study consists of two separate parts: a model of the MR pre-cooling step, and a model of the cryogenic-cooling step cycle compressor. The development of these two models is described below. A block diagram showing the relationship between the cryogenic-cooling step and the pre-cooling step is also presented in Appendix A.

Figure 1 illustrates the process flow scheme used for the MR pre-cooling process, which is based on the flow scheme used in the reference study of Skaugen, et al. [13]. The main equipment items are a compressor (comprising RC-1 and RC-2), two process coolers (PC-1 and PC-2), a MR separator (VV-1), a pump (PP-1), and the main heat-exchanger (HX-1). The MR compressor comprises two stages (RC-1 \& 2), both with after-cooling (PC$1 \& 2$ ) to $T_{c}$. Any liquids condensed liquids after the first stage are separated in VV-1. Liquids separated in this way are pumped (PP-1) to the compressor discharge pressurebypassing the second stage of compression ( $\mathrm{RC}-2)$ - and mixed with the vapour stream entering the main exchanger (HX-1). The main exchanger is modelled as a multi-stream type exchanger with two hot streams: $\mathrm{H}_{2}$ and high-pressure $\mathrm{MR}$, and one cold stream: low-pressure MR. The low-pressure MR stream exiting the main exchanger returns to the MR compressor. Hydrogen leaving $\mathrm{HX}-1$ is cooled to $T_{\mathrm{p}}$. 


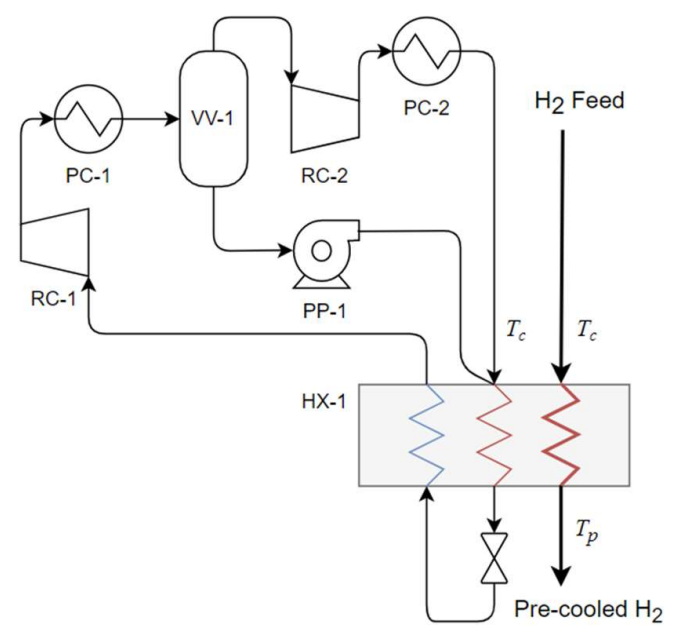

Figure 1. Flow diagram for the $\mathrm{MR} \mathrm{H}_{2}$ pre-cooling process.

To allow the calculation of process energy consumption a simplified model of the process presented in Figure 1 was developed in MATLAB [22] with the TREND software package [23] used to calculate thermo-physical properties. Table 1 presents the set of fixed modelling parameters, MP, used in the model of the MR pre-cooling process. In general, the parameters in Table 1 were selected to reflect those used in the reference study [13].

Table 1. Summary of MR process fixed modelling parameters.

\begin{tabular}{ccc}
\hline Hydrogen feed pressure & 20 & bara \\
H2 pre-cooling temperature, $T_{p}$ & -159 & ${ }^{\circ} \mathrm{C}$ \\
Compressor/ pump efficiency & 85 & $\%^{*}$ \\
HX-1 pressure-loss (hot streams) & 0.5 & bar \\
HX-1 pressure-loss (cold streams) & 0.1 & bar \\
PC-1 \& 2 pressure-loss & 0.5 & bar \\
\hline
\end{tabular}

* Isentropic efficiency

For simplicity, the pressure-loss in the main exchanger was scaled linearly with temperature and the two MR streams were assumed to be mixed before entering the heat exchanger and the combined MR stream enters the main exchanger at the $\mathrm{H}_{2}$ feed temperature.

The temperature profiles for the combined hot streams and the cold stream in HX1 - the hot and cold composite curves - were estimated by splitting the exchanger into $n$ equally sized temperature intervals, each sized $\left(T_{\text {in }}-T_{\text {out }}\right) / n$ and stream enthalpies calculated for each temperature point $(n+1$, total). Then the exchanger duty was also split into $n$ equally sized intervals $\left(Q_{\mathrm{HX}-1} / n\right)$, and the hot and cold composite temperatures, $T_{\mathrm{HC}}$ and $T_{\mathrm{CC}}$, interpolated at each point $(n+1$, total) using linear interpolation of the temperature-enthalpy data. Finally, the temperature approach was calculated for each point, $\Delta T=T_{\mathrm{HC}}-T_{\mathrm{CC}}$. In both cases, $n$ was set to 50 to give a high degree of accuracy to the calculations.

Figure 2 provides a sketch of the cycle compressor (comprising H2-1 to 4) for the cryogenic-cooling step which forms the basis of the present study. The stream LP H2 represents the low-pressure hydrogen stream returning from the liquefaction process. This stream is compressed in two compressor stages (H2-1 and H2-2) before blending with medium-pressure hydrogen. The combined stream is then compressed in two further compressor stages (H2-3 and H2-4) before being passed-back to a multi-stream exchanger (HX-2), which cools the HP stream down to $T_{\mathrm{p}}$. The compressor inter-stage pressures are calculated assuming equal stage pressure ratios. 


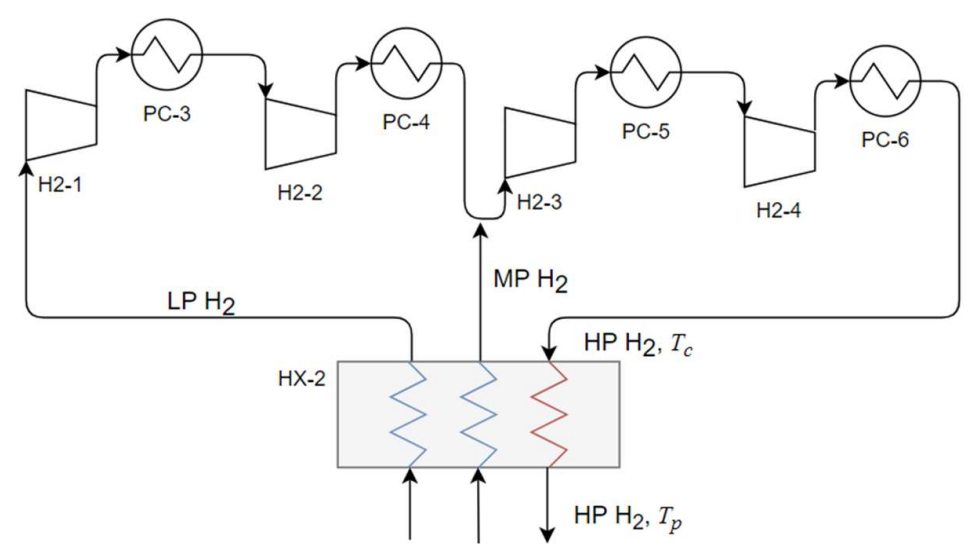

Figure 2. Flow diagram of the cryogenic-cooling step $\mathrm{H}_{2}$ cycle compressor.

The model of the cryogen-cooling step compressor was also developed in MATLAB using the same basis as the MR process model. Table 2 presents the fixed modelling parameters used in the study performance of this compressor, which are based on the reference model [13]. The outlet temperature of the four after-coolers (PC-3 to 6) were assumed equal to $T_{\mathrm{c}}$ and the inlet temperature of the LP and MP streams to the compressor was assumed to have a $2{ }^{\circ} \mathrm{C}$ approach to $T_{\mathrm{c}}$ in all cases.

Table 2. Summary of fixed modelling parameters for the cryogenic-cooling cycle compressor

\begin{tabular}{ccc}
\hline LP H2 feed pressure & 1.1 & bara \\
LP H2 flowrate & 51.5 & tpd \\
MP H2 feed pressure & 8.0 & bara \\
MP H2 flowrate & 1121.5 & tpd \\
HP H2 return pressure & 29.8 & bara \\
PC-3 to 6 pressure-loss & 0.5 & bar \\
\hline *Isentropic efficiency
\end{tabular}

In addition to the cycle compressor, the reference study describes several turbo-expanders within the cryogenic cooling step. These produce 2.8 MW of shaft power, which is assumed in the reference study to be recovered as electrical energy with as efficiency of $80 \%$ [13]. Assuming - as before - that the parameters in the cryogenic process remain constant with varying $T_{\mathrm{c}}$, this recovered energy equates to a specific energy production for the expanders, $\mathrm{SEC}_{\mathrm{Ex}}$, of approximately $0.43 \mathrm{kWh} / \mathrm{kg}$, which is a constant value for all cases studied in this work.

Where operating parameters were not available in the reference study, they have been inferred from the data that is presented there. Because of this, it cannot be claimed that there is any direct equivalence between the results presented here and the reference model.

\subsection{MR Pre-cooling Model Validation}

An important aspect of successful optimization is the minimization of temperature differences in HX-1, and since the targeted minimum approach temperature is only $1 \mathrm{~K}$, the accuracy of the property predications used in the process model is very important. In the TREND software package, several properties methods are available; to select the basis that is most appropriate for the present work, three of these were compared against results from the reference study: Peng Robinson (PR), Soave-Redlich-Kwong (SRK), and the TREND Helmholtz free energy model. Tables 3 and 4 present the parameters used in the validation work. The results of the validation work were used to select the properties method used in the later optimization work. 
Table 3. Validation case MR composition.

\begin{tabular}{cc}
\hline Component & Mole fraction \\
\hline Nitrogen & 0.101 \\
Methane & 0.324 \\
Ethane & 0.274 \\
Propane & 0.031 \\
n-Butane & 0.270 \\
\hline
\end{tabular}

Table 4. Validation case MR modelling parameters.

\begin{tabular}{ccc}
\hline Hydrogen feed flow & 125 & tpd \\
MR feed temperature & 12 & ${ }^{\circ} \mathrm{C}$ \\
MR return temperature & -1 & ${ }^{\circ} \mathrm{C}$ \\
MR feed pressure & 35 & bara \\
MR return pressure & 4.25 & bara \\
\hline
\end{tabular}

\subsection{Optimization Problem Defenition}

The objective of the optimization study was to minimize the energy consumption of the MR pre-cooling process whilst satisfying a minimum temperature approach constraint. The objective function was formulated as follows:

$$
\min \left\{\mathrm{SEC}_{\mathrm{MR}}\right\} \text {, such that }\left\{\begin{array}{c}
\mathrm{lb}_{i}<\mathrm{OP}_{i}<\mathrm{lb}_{i} \\
\Delta T_{\min }-\Delta T_{\mathrm{acc}}>0 \\
\dot{m}_{\mathrm{MR}}>0
\end{array}\right.
$$

where $\mathrm{SEC}_{\mathrm{MR}}$ is the specific energy consumption of the MR process, $\mathrm{OP}_{i}$ are the set of $i$ optimization parameters (see Table 5), $\mathrm{lb}_{i}$ and $\mathrm{ub}_{i}$ are a set of lower and upper bounds for each parameter, $\Delta T_{\min }$ is the minimum approach temperature in HX-1 $\left(\Delta T_{\min }=\min \left\{\Delta T_{n}\right\}\right), \Delta T_{\text {acc }}$ is the minimum acceptable approach temperature in $\mathrm{HX}-1$ and $\dot{m}_{\mathrm{MR}}$ is the mass flowrate of the MR. $\mathrm{SEC}_{\mathrm{MR}}$ was calculated from the sum the compression stage energy consumptions, $W_{\mathrm{MR}}$, which are, in turn, a function of $\mathrm{OP}_{i}, \mathrm{MP}_{i}$ (see Table 1) and $T_{\mathrm{c}}$ :

$$
\mathrm{SEC}_{\mathrm{MR}}=\sum W_{\mathrm{MR}}\left(\mathrm{OP}_{i}, \mathrm{MP}_{i}, T_{\mathrm{c}}\right) / \dot{m}_{\mathrm{H} 2}
$$

where $\dot{m}_{\mathrm{H} 2}$ is the mass flowrate of hydrogen.

The set of optimization parameters, $\mathrm{OP}_{i}$, used in the study are summarised in Table 4 along with the initial values used $\left(\mathrm{OP}_{i, 0}\right)$ and initial values of the boundary constraints $\left(\mathrm{lb}_{i}\right.$ and $\left.\mathrm{ub}_{i}\right)$.

Table 5. Summary of Optimization Parameters with Initial $\left(\mathrm{OP}_{i, 0}\right)$ and Constraint Values.

\begin{tabular}{ccc}
\hline Parameter & Description & $\mathbf{I b}_{\boldsymbol{i}}<\mathbf{O P}_{\boldsymbol{i}, \mathbf{0}}<\mathbf{u b}$ \\
\hline $\mathrm{OP}_{1}$ & MR mole fraction N2 & $0.05<0.11<0.25$ \\
\hline $\mathrm{OP}_{2}$ & Mole fraction CH4 & $0.20<0.32<0.50$ \\
\hline $\mathrm{OP}_{3}$ & MR mole fraction C2 & $0.15<0.27<0.50$ \\
\hline $\mathrm{OP}_{4}$ & MR mole fraction C3 & $0.00<0.03<0.10$ \\
\hline $\mathrm{OP}_{5}$ & RC-1, Pin (bara) & $2.00<4.25<6.00$ \\
\hline
\end{tabular}

Although the ultimate purpose of the boundary constraints was to limit the optimization process to physically meaningful solutions - e.g., component mole fractions greater than zero - the initial boundary constraints were also used to limit the search area around the likely optimum values. This was done to reduce optimization time. The initial values of $\mathrm{lb}$ and $\mathrm{ub}$ shown in Table 5 were set based on results from the reference case, but where the optimization solution was found close to the initial limits, the bounds were extended to ensure that the overall optimum solution was not missed. 
In addition to the optimization parameters listed in Table 5, the MR compressor interstage pressure, MR compressor discharge pressure and HX-1 warm-end approach temperature could be considered as optimization parameters. However, in this work these have been excluded to limit complexity. The MR compressor discharge pressure is, therefore, fixed at the value used in the reference study, the MR inter-stage pressure set in each case to maintain equal stage pressure ratios, and the $\mathrm{HX}-1$ warm-end approach set to $5{ }^{\circ} \mathrm{C}$. The MR mole fraction for butane is also not identified as an optimization parameter because it is calculated from the sum of the other components.

\subsection{Optimization Algorithm}

In a phase of initial testing the Fmincon (FMC) algorithm with the SQP option was found to provide fast and generally accurate optimization results, although in some cases local minima were found. In all subsequent cases, FMC was used with the solution tolerance set to $0.001 \mathrm{kWh} / \mathrm{kg}$ and all other options left as default.

To help identify the global minimum solutions for each $T_{\mathrm{c}}$, the boundary constraints shown in Table 5 were evaluated in a manual, stepwise, process: after the initial results had been gathered, new initial guesses were specified when the original initial guess was found to be a long way from the solution. When a stable set of bounds enclosing the global solution had been found, the MultiStart, MS, and GlobalSearch, GS, algorithms were used to help test the quality of the results. In both cases the MS and GS runs were again based on the FMC algorithm with the parameters as before.

The quality each optimization result was assessed qualitatively using the results from other $T_{\mathrm{c}}$ cases. The basis of this assessment was the assumption that a simple, monotonic, relationship was likely between each of the optimization parameters and $T_{\mathrm{c}}$. In addition to this assessment, the temperature profiles in HX-1 for each case were reviewed qualitatively to determine if $\Delta T_{\text {acc }}$ was consistently approached throughout the exchanger.

\subsection{Performance Variation with Cooling Temperature}

Performance variation with cooling temperature was studied for the MR pre-cooling process by finding the optimum operating parameters, $\mathrm{OP}_{i}$, for each cooling temperature, $T_{\mathrm{c}}$ case. The fixed modelling parameters shown in Table 2 were used as the basis in all cases. The cooling temperature range studied was 5 to $50{ }^{\circ} \mathrm{C}$.

In the model developed for the cryogenic-cooling step, process parameters were not optimized: flowrates and pressure levels in the cryogenic cycle were held constant at the values shown in Table 3. The variation of the energy consumption of the cryogenic cycle compressor with $T_{c}$ was modelled using the more simplistic assumption that, since the composite cooling curves in HX-2 are straight and parallel, a constant warm-end approach temperature exists across the range of cooling temperatures studied. The energy consumption of the cryogenic cycle compressor was calculated using the same basis as that of the MR pre-cooling process. A $2{ }^{\circ} \mathrm{C}$ warm-end approach temperature was assumed across the cooling temperature range 5 to $50{ }^{\circ} \mathrm{C}$.

The overall SEC for the hydrogen liquefaction process was calculated as the sum of the energy consumption for the $\mathrm{MR}$ pre-cooling step, $\mathrm{SEC}_{\mathrm{MR}}$, and the cryogenic-cooling step, $\mathrm{SEC}_{\mathrm{CY}}$, which was-in turn - calculated as the sum of the cycle compressor stage energy consumptions minus the energy recovered in the cryogenic-cooling step expanders:

$$
\begin{gathered}
\mathrm{SEC}=\mathrm{SEC}_{\mathrm{MR}}+\mathrm{SEC}_{\mathrm{CY}} \\
\mathrm{SEC}_{\mathrm{CY}}=\sum W_{\mathrm{H} 2}\left(\mathrm{MP}_{\mathrm{H} 2}, T_{c}\right) / \dot{m}_{\mathrm{H} 2}-\mathrm{SEC}_{\mathrm{Ex}}
\end{gathered}
$$

where $W_{\mathrm{H} 2}$ is the energy consumption of the cycle compressors shown in Figure 2, and $\mathrm{MP}_{\mathrm{H} 2}$ are the fixed modelling parameters for the cryogenic-cooling cycle compressor (see Table 2).

To provide an independent means of reviewing the trends shown in the results, the SEC for an ideal process that cooled the hydrogen from $T_{\mathrm{c}}$ to a final temperature of -259 
${ }^{\circ} \mathrm{C}$ was also calculated. This ideal energy consumption, $\mathrm{SEC}_{\mathrm{ID}}$, was then used to calculate a second law efficiency, $\eta_{\text {id }}=\mathrm{SEC} / \mathrm{SEC}_{\mathrm{ID}}$, for the overall process. The method used to calculate $\mathrm{SEC}_{\mathrm{ID}}$ was to summate the ideal Carnot cycle energy consumption for a set of very small temperature steps along temperature-enthalpy data for hydrogen as explained previously by Jackson, et al. [20].

\section{Results}

\subsection{Process Modelling and Validation}

Table 5 shows the results from the model validation work. In addition to the results from the reference study, three sets of results are presented: Case A uses the TREND implementation of the Peng Robinson (PR) equation of state; Case B the TREND/ SRK equation of state; and Case $C$ the TREND/ Helmholtz free energy properties method.

Table 5. Summary of modelling parameters for the model validation work.

\begin{tabular}{|c|c|c|c|c|c|}
\hline & Reference & Case A & Case B & Case C & \\
\hline Properties method & - & $\mathrm{PR}$ & SRK & Hel. & \\
\hline MP supply pressure & 35 & 35 & 35 & 35 & bara \\
\hline MR return pressure & 4.25 & $3.0^{* *}$ & 4.25 & 4.25 & bara \\
\hline MR return temp. & 112 & 112.8 & 112.3 & 109.6 & ${ }^{\circ} \mathrm{C}$ \\
\hline MR mass flowrate & $1600^{*}$ & 1395 & 1703 & 1709 & tpd \\
\hline HX-1 min. approach & 1.0 & 1.05 & 0.49 & 0.51 & ${ }^{\circ} \mathrm{C}$ \\
\hline HX-1 duty & 12.6 & 11.2 & 13.2 & 12.9 & $\mathrm{~kW}$ \\
\hline
\end{tabular}

${ }^{*}$ Given only as an approximate value in the reference case.

** Adjusted to give a positive value for min. approach.

Of the three cases compared, Case C-using the TREND/ Helmholtz free energy properties method - is considered to represent the closest match to the reference case, but since Case B also offers good agreement and significantly reduced calculation time, SRK is selected as the basis for further work.

Figure 3 presents the composite temperature profile data for Case B and C in Table 5. The results show that, although the shape of the curves differs between the two cases, the results from both cases show a very good fit between the warm and cold curves throughout the exchanger. These results, therefore, add confidence to the validation work and the selection of Case B as the modelling basis.

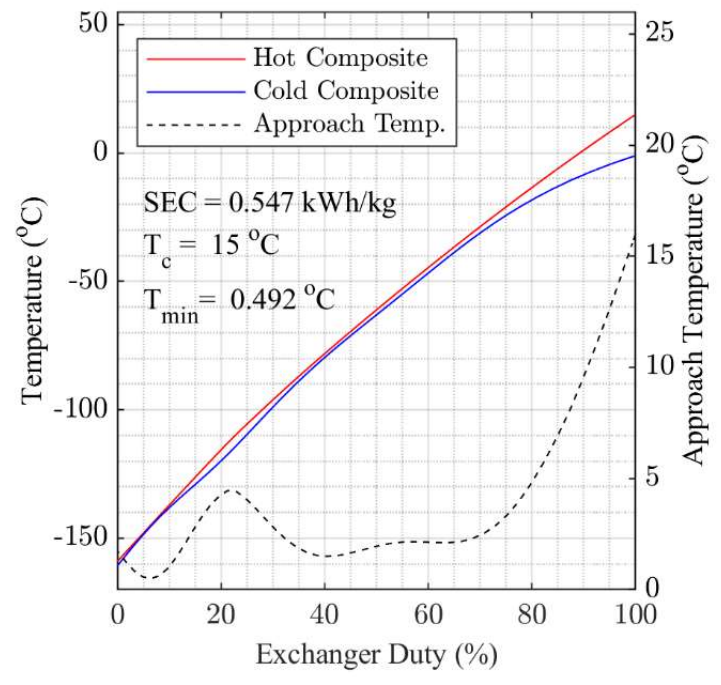

(a)

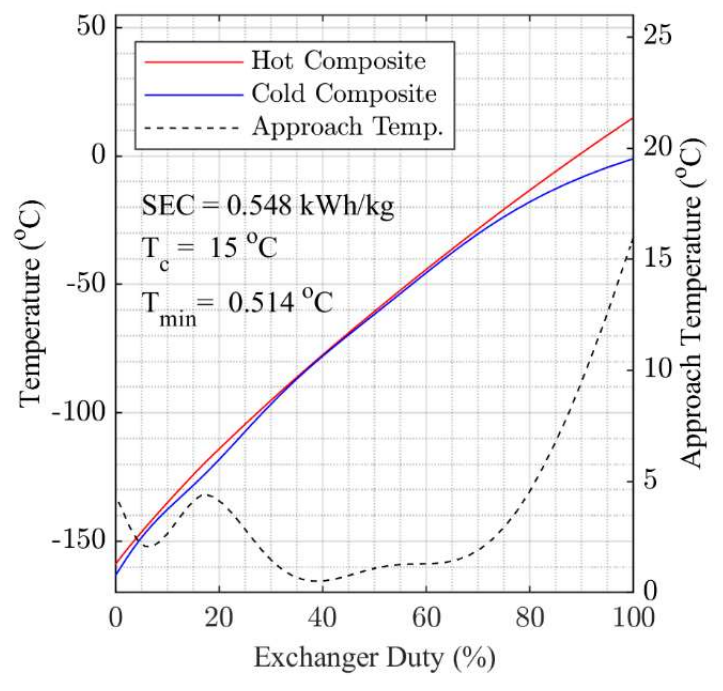

(b) 
Figure 3. Composite Curves HX-1, MR Pre-cooling Process: (a) Case B (b) Case C.

\subsection{Performance Variation with Cooling Temperature}

Figures 4 and 5 show how the five optimization parameters vary with $T_{\mathrm{c}}$ and Figures 6 and 7 provide two examples of the optimized cooling curves resulting from these runs. In Figures 4 and 5 all of the data collected over the final set of optimization runs (two using GS and two using MS) are presented as points and the overall optimum datasets are connected by dotted lines.

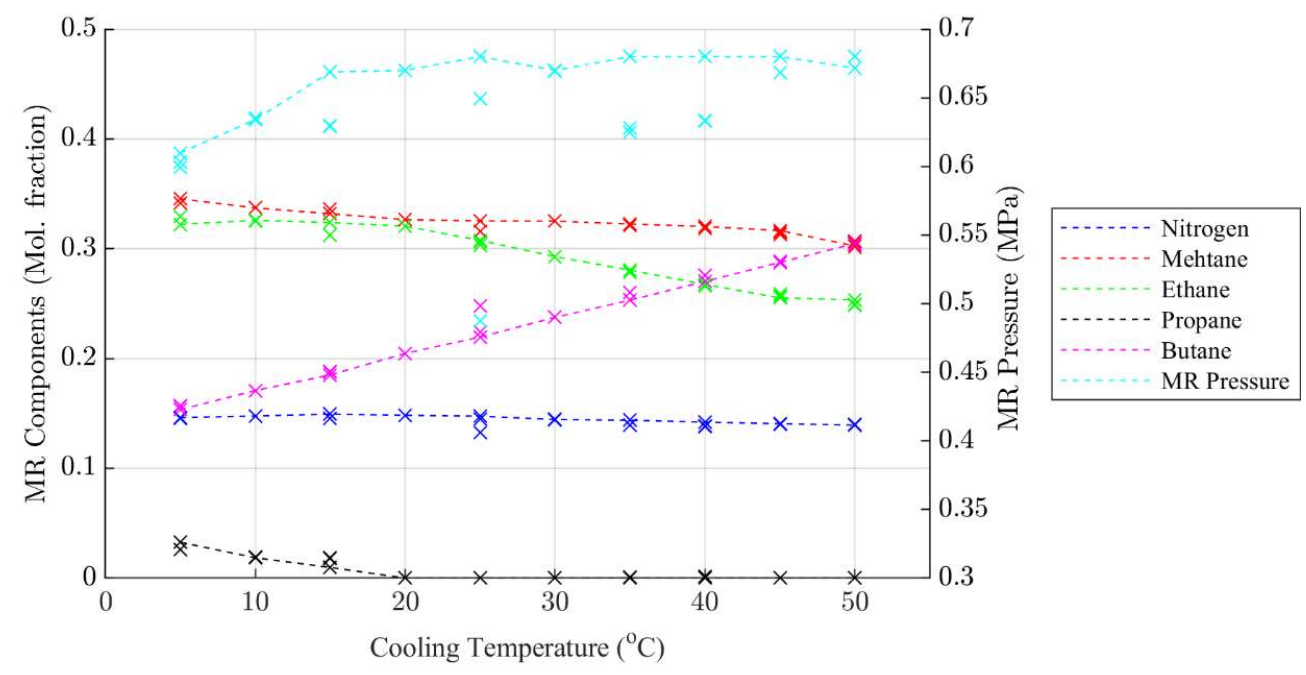

Figure 4. Variation in OP for the MR pre-cooling step with cooling temperature.

The results presented in Figure 4 for MR composition show quite clear trends; the data for the MR pressure is less consistent. This indicates that the optimum combination of MR composition and MR operating pressure is difficult to determine and that the overall minimum may not have been found in all cases. However, Figure 5 shows a very consistent trend in how SEC varies with $T_{c}$, which provides confidence that a solution close to the overall minimum was found in most cases.

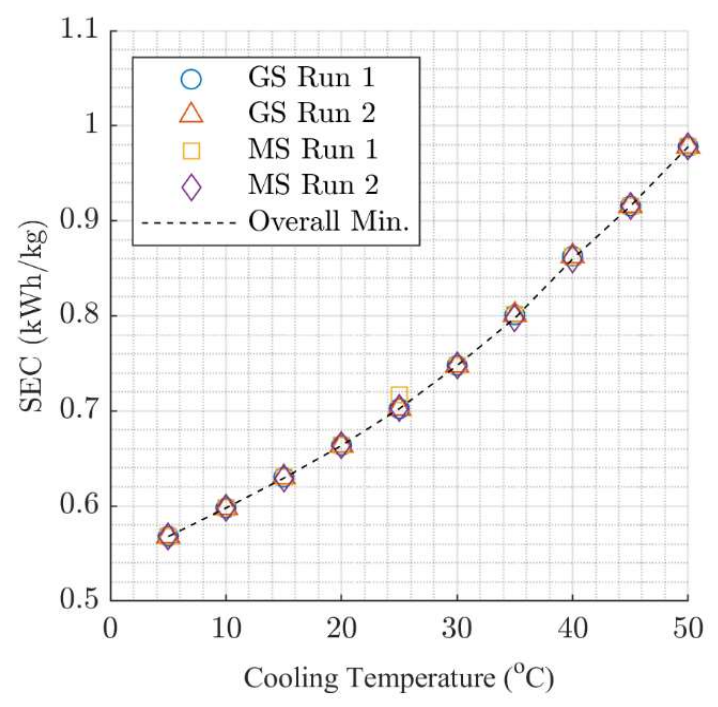

Figure 5. Variation in SEC for the MR pre-cooling step with cooling temperature. 
Figures 6 and 7 present the hot and cold composite cooling curves for the overall minimum solutions found for $T_{\mathrm{c}}=5{ }^{\circ} \mathrm{C}$ and $T_{\mathrm{c}}=50^{\circ} \mathrm{C}$. These results show that the optimization algorithm has found a good fit for the cooling curves, which adds confidence in the overall results.

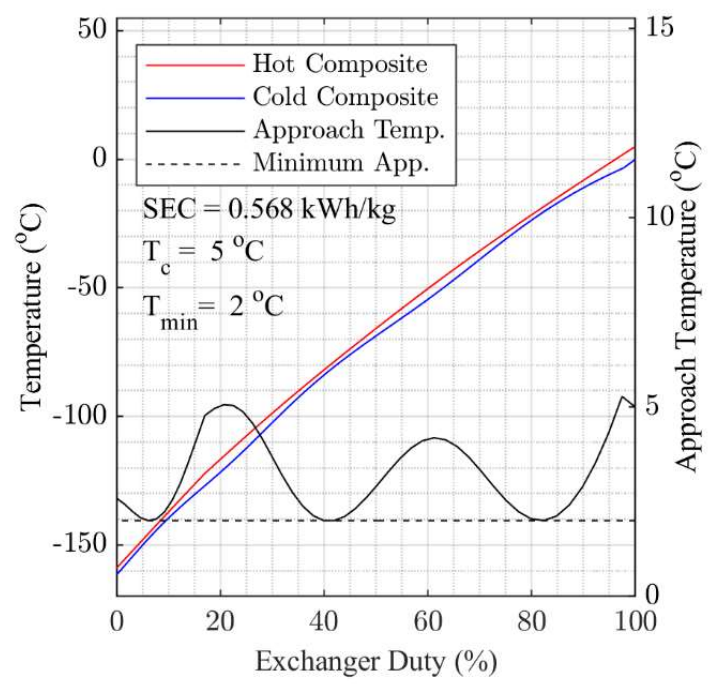

Figure 6. Variation in overall hydrogen liquefaction SEC with cooling temperature.

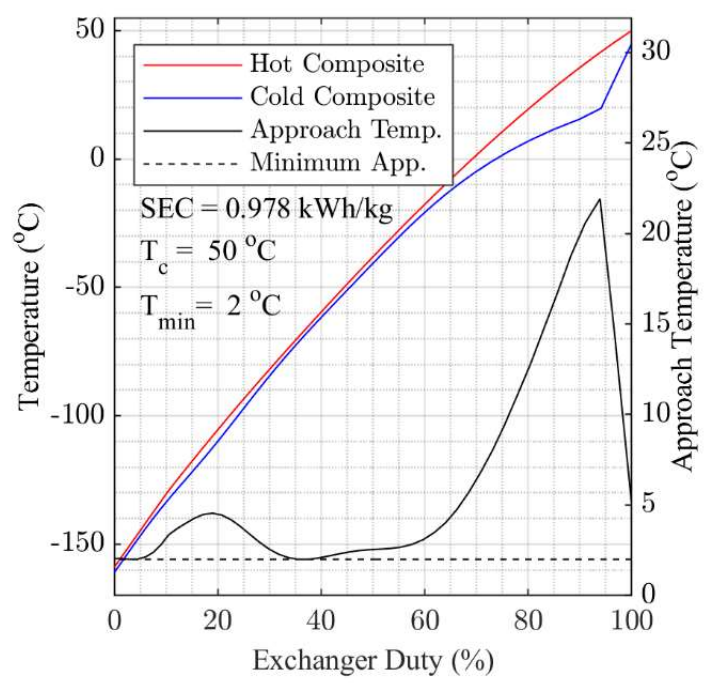

Figure 7. Percentage variation in overall SEC and second law efficiency.

Figure 8 presents the SEC for the pre-cooling step, the cryogenic-cooling step, and the overall process. Figure 9 presents the same data in terms of the \% change from the 25 ${ }^{\circ} \mathrm{C}$ case. Presented in Figure 9 are the corresponding second law efficiencies expressed as a percentage.
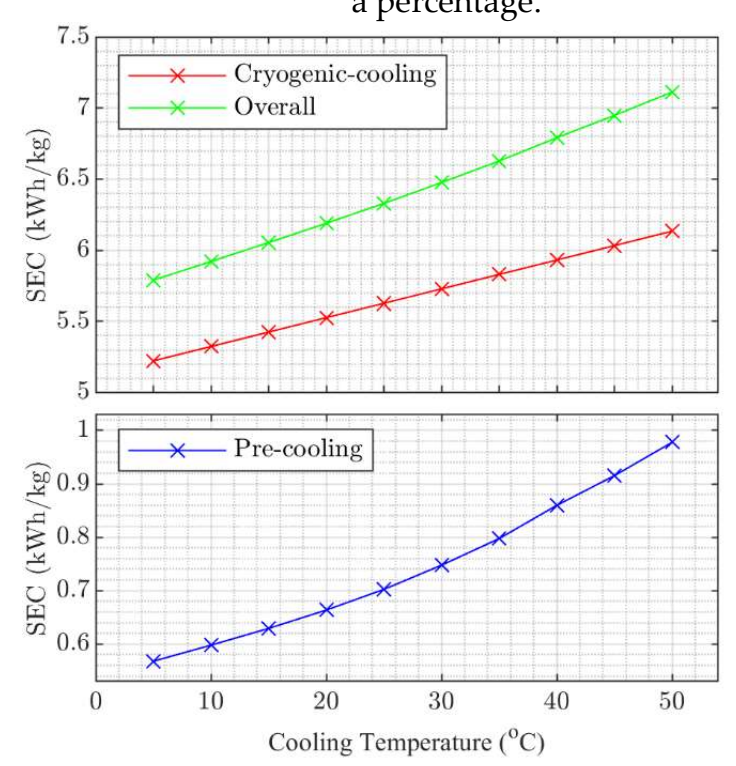

Figure 8. Variation in overall hydrogen liquefaction SEC with cooling temperature.

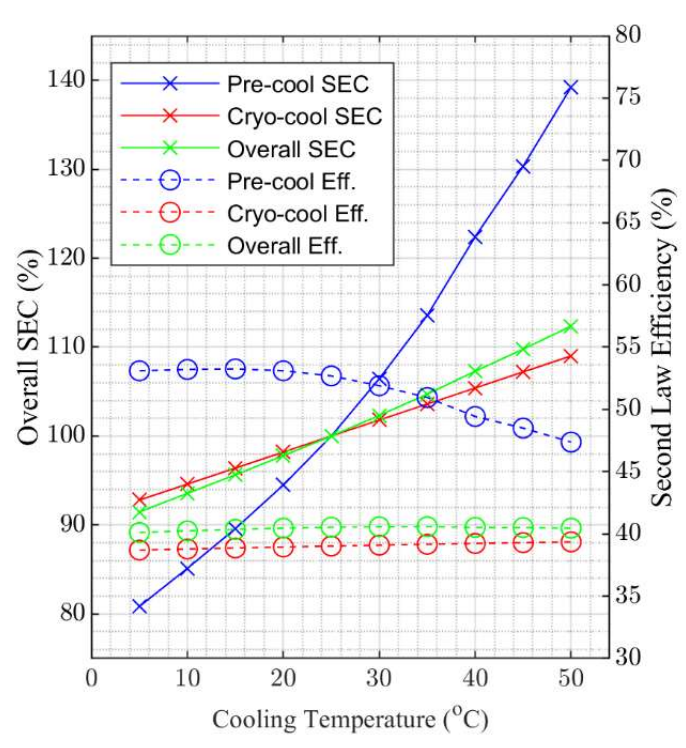

Figure 9. Percentage variation in overall SEC and second law efficiency.

Figure 8 shows that the cryogenic part of the process represents the larger part of overall energy demand and therefore has the greater impact on overall power. Figure 9 shows that SEC increases by roughly $20 \%$ over the range considered: $2 \%$ for each $5{ }^{\circ} \mathrm{C}$ variation in temperature. Figure 9 also shows that, while the second law efficiency of the 
cryogenic-cooling process is close to constant across the range of temperatures considered, the efficiency of the pre-cooling process drops significantly. The cause of this drop in efficiency as the cooling temperature increase can be seen in Figure 6 and Figure 7, which show that the mean temperature difference for the higher temperature cases is higher than that of the lower temperature cases.

\section{Discussion}

Table 5 shows that the selection of a good modelling basis is important to the determination of the optimum operating parameters for this process. No claim is made here that the modelling basis selected is the one that is most accurate for the modelling of this process, just that it provided a good match with the reference case in the validation work presented. The impact of heat generated during ortho-para hydrogen conversion is omitted form the model, which is a simplification that limits the extent to which this modelling work reflects the performance of a hydrogen liquefaction process operating in the real world. The main claim made here regarding the modelling basis is that it provides provide a consistent basis to study performance across the operating cases considered. Based on this, the study of the variation in energy consumption with cooling temperature is valid and can provide some insight into how the performance real hydrogen liquefaction processes can be expected to vary when designed for utility cooling at different temperatures.

The results for the final set of optimization runs show some inconsistent trends. For example, in Figure 4 shows that the optimum MR pressure does not increase uniformly with temperature. This indicates that the overall optimum set of operating parameters has not been found in all cases. Altering the optimization approach with more search points or extended run-time could provide a way of improving the optimization results. However, the results in Figure 5 show consistent trends in the variation of SEC with temperature, which suggests that the minimum energy cases presented should be very close to the overall minimum, and for this study that is considered sufficient to meet the aims of the research work.

The results presented in Figures 6 and 7 show that the optimization process has found parameters that minimize the temperature approach in $\mathrm{HX}-2$, but also that as the cooling temperature increases it becomes more difficult to maintain a close approach in the warm end of the exchanger. This is reflected in Figure 9, which shows that the performance of the pre-cooling process compared to an ideal process decreases as the cooling temperature increases. This could be countered by adding heavier components to the MR or adding pressure levels to the MR compressor. However, both of these measures are not considered in the present study.

\section{Conclusions}

A model for a hydrogen liquefaction process has been developed and validated against results from an independent study. Although the validation process highlighted the significant impact that different properties models can have on model predictions, the validation results did indicate that the present model is suitable for the study of the impact of ambient temperature on process performance.

A set of optimization parameters were selected, and an optimization method developed that was suitable for the study of process performance across a range of process cooling temperatures. The results of the optimization work show that the specific energy consumption, SEC, of the MR pre-cooling process increases by around $80 \%$, from approximately 0.57 to $1.0 \mathrm{kWh} / \mathrm{kg}$, across the cooling temperature range 5 to $50{ }^{\circ} \mathrm{C}$. These results combined with the calculated process performance for the cryogenic-cooling step (not optimized here), show that total energy consumption for the hydrogen liquefaction process increases by around $20 \%$, from 5.8 to $7.1 \mathrm{kWh} / \mathrm{kg}$, across the same temperature range. Considering just the range 20 to $30{ }^{\circ} \mathrm{C}$ there is a $5 \%$ increase, which illustrates the significant impact ambient temperature can have on energy consumption. 
The variation in energy consumption with cooling temperature implies a significant benefit for liquefaction processes operating in low ambient temperature locations, especially given that the hydrogen liquefaction process represents a very energy intensive step in the supply of liquid hydrogen. The aim of further work is to combine these results into a larger system model that considers the impact of ambient temperature on the supply of low-carbon energy from natural gas.

Author Contributions: Conceptualization, S.J.; methodology, S.J. and E.B.; validation, S.J.; formal analysis, S.J.; investigation, S.J.; data curation, S.J.; writing-original draft preparation, S.J.; writing-review and editing, S.J. and E.B.; supervision, E.B.

Funding: This research received no external funding.

Conflicts of Interest: The authors declare no conflict of interest.

\section{Appendix A}

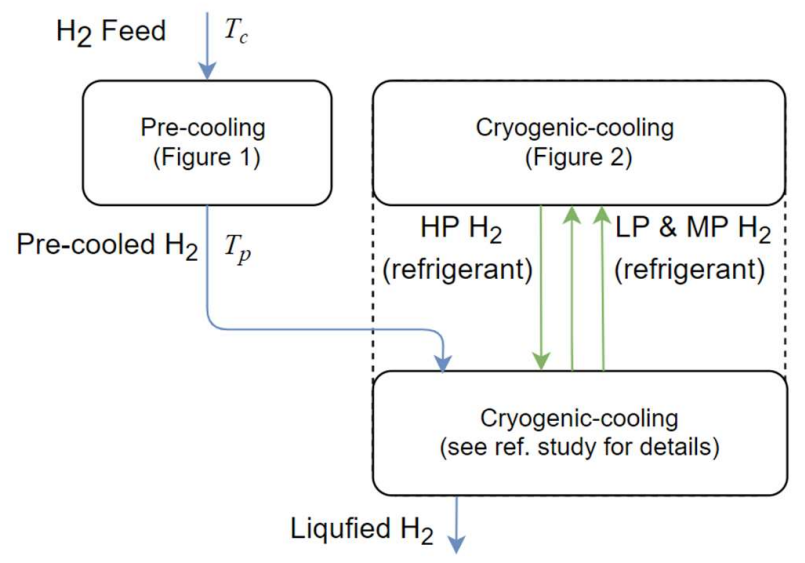

Figure A1. Block flow diagram of the overall liquefaction process.

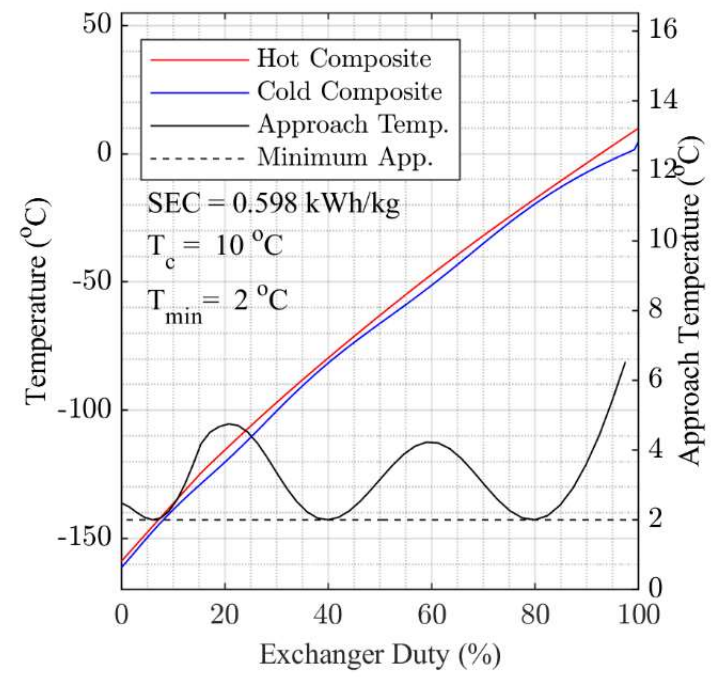

Figure A2. Optimized composite cooling curves for $10^{\circ} \mathrm{C}$ cooling temperature.

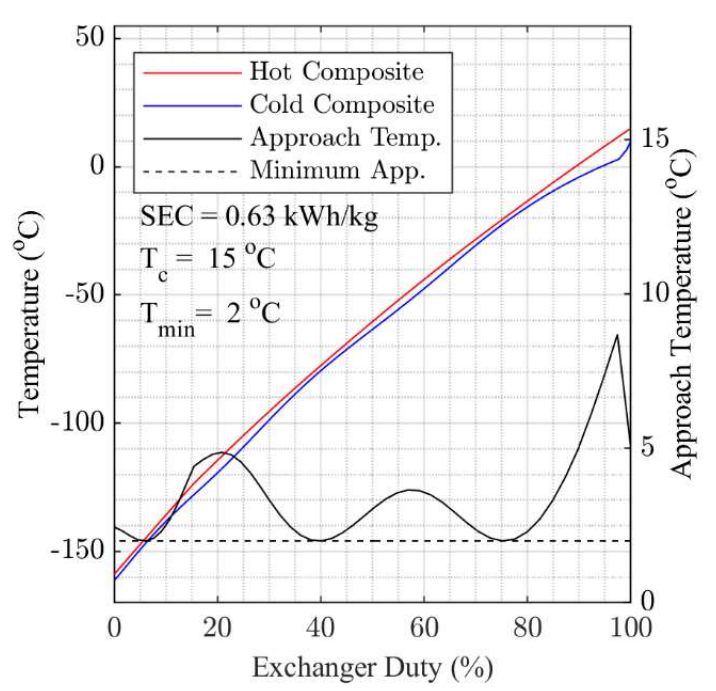

Figure A3. Optimized composite cooling curves for $15^{\circ} \mathrm{C}$ cooling temperature. 


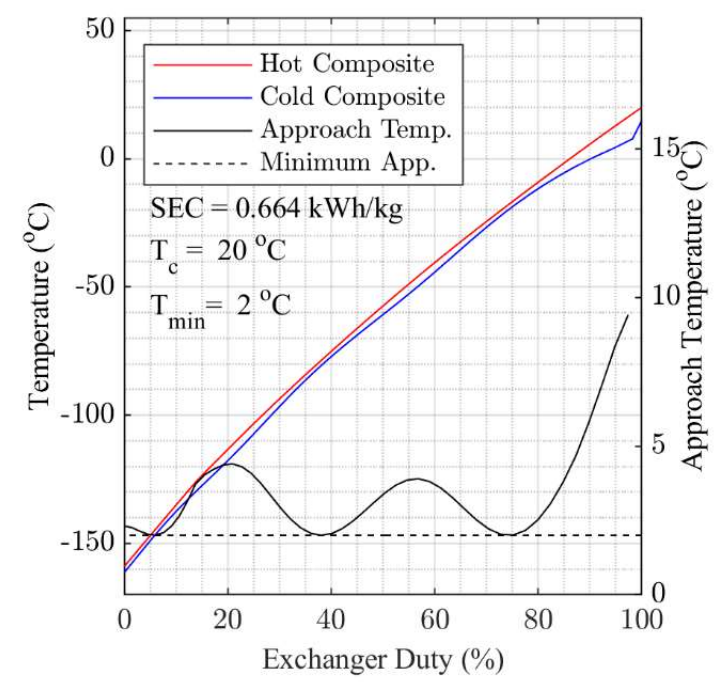

Figure A4. Optimized composite cooling curves for $20^{\circ} \mathrm{C}$ cooling temperature.

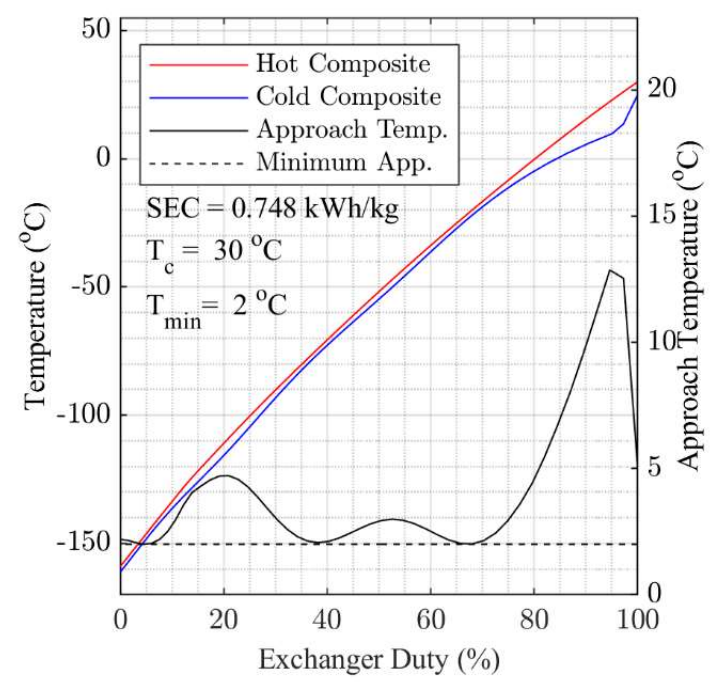

Figure A6. Optimized composite cooling curves for $30^{\circ} \mathrm{C}$ cooling temperature.

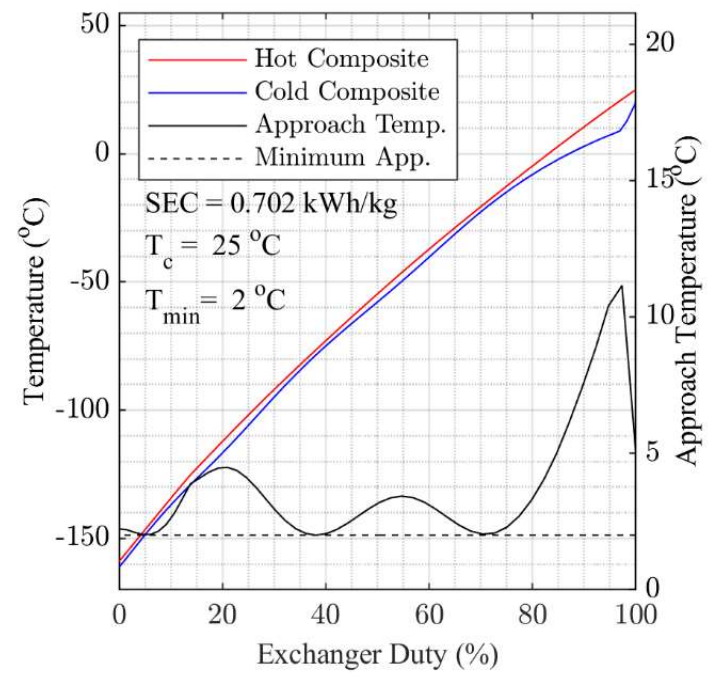

Figure A5. Optimized composite cooling curves for $25^{\circ} \mathrm{C}$ cooling temperature.

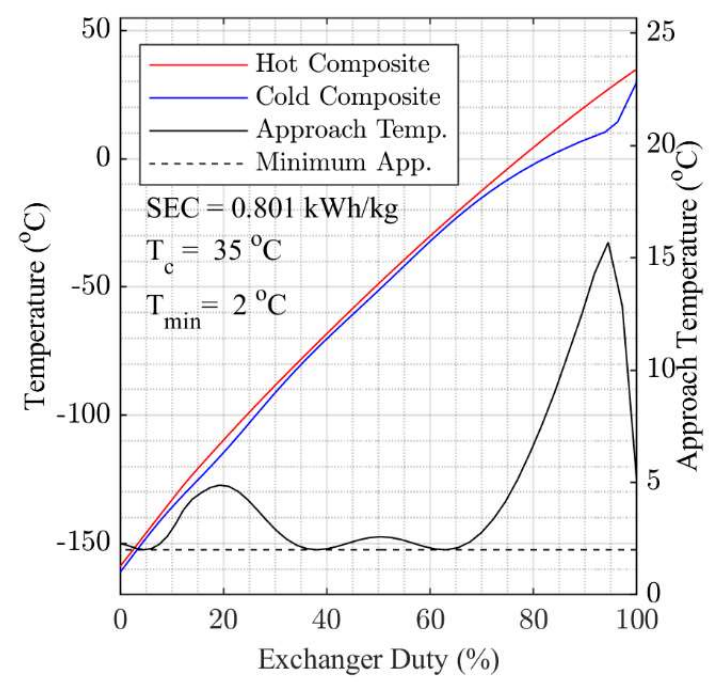

Figure A7. Optimized composite cooling curves for $35^{\circ} \mathrm{C}$ cooling temperature. 


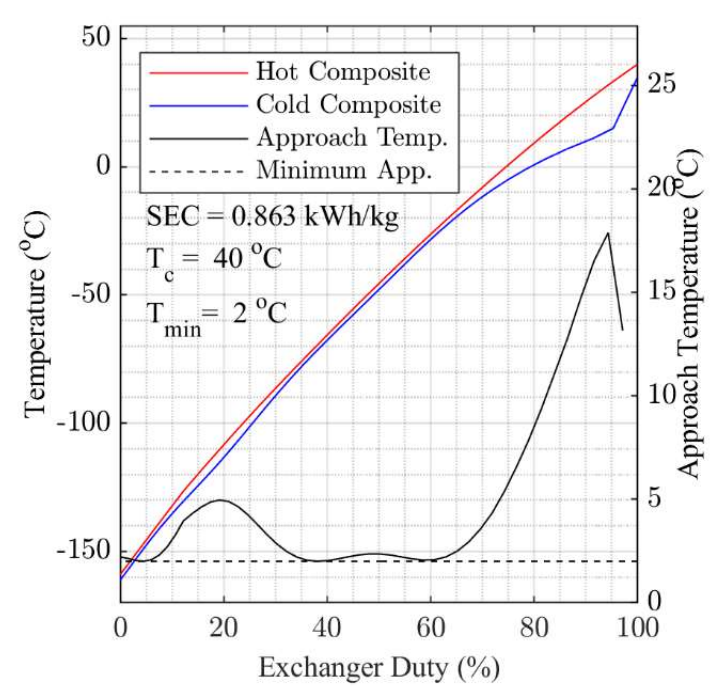

Figure A8. Optimized composite cooling curves for $40^{\circ} \mathrm{C}$ cooling temperature.

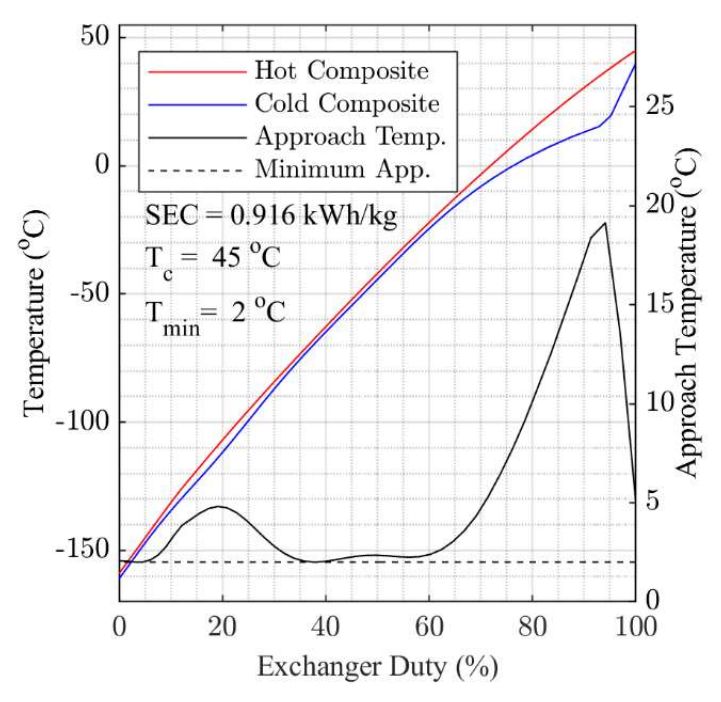

Figure A9. Optimized composite cooling curves for $45^{\circ} \mathrm{C}$ cooling temperature.

\section{References}

1. Cells, F.; Undertaking, H.J. Hydrogen Roadmap Europe-A Sustainable Pathway for the European Energy Transition. 2019, doi:10.2843/341510.

2. Moya, J.; Ioannis; Dalius; Wouter. Hydrogen use in EU decarbonisation scenarios. 2019.

3. The European Comission. A hydrogen strategy for a climate-neutral Europe. 2020.

4. Kang, J.-N.; Wei, Y.-M.; Liu, L.-C.; Han, R.; Yu, B.-Y.; Wang, J.-W. Energy systems for climate change mitigation: A systematic review. Applied Energy 2020, 263, 114602, doi:https://doi.org/10.1016/j.apenergy.2020.114602.

5. Yuksel, Y.E.; Ozturk, M.; Dincer, I. Energetic and exergetic assessments of a novel solar power tower based multigeneration system with hydrogen production and liquefaction. International Journal of Hydrogen Energy 2019, 44, 13071-13084, doi:10.1016/j.ijhydene.2019.03.263.

6. Yang, C.; Ogden, J. Determining the lowest-cost hydrogen delivery mode. International Journal of Hydrogen Energy 2007, 32, 268-286, doi:https://doi.org/10.1016/j.ijhydene.2006.05.009.

7. Ishimoto, Y.; Voldsund, M.; Nekså, P.; Roussanaly, S.; Berstad, D.; Gardarsdottir, S.O. Large-scale production and transport of hydrogen from Norway to Europe and Japan: Value chain analysis and comparison of liquid hydrogen and ammonia as energy carriers. 2020, 32865-32883, doi:10.1016/j.ijhydene.2020.09.017.

8. Hoshi, M. World's first liquid hydrogen carrier ship launches in Japan. Available online: https://asia.nikkei.com/Business/Energy/World-s-first-liquid-hydrogen-carrier-ship-launches-in-Japan (accessed on 15.04.2021).

9. Aasadnia, M.; Mehrpooya, M. Large-scale liquid hydrogen production methods and approaches: A review. Applied Energy 2018, 212, 57-83, doi:https://doi.org/10.1016/j.apenergy.2017.12.033.

10. Ghorbani, B.; Mehrpooya, M.; Aasadnia, M.; Niasar, M.S. Hydrogen liquefaction process using solar energy and organic Rankine cycle power system. Journal of Cleaner Production 2019.

11. Yilmaz, C. Optimum energy evaluation and life cycle cost assessment of a hydrogen liquefaction system assisted by geothermal energy. International Journal of Hydrogen Energy 2019. 
12. Ansarinasab, H.; Mehrpooya, M.; Mohammadi, A. Advanced exergy and exergoeconomic analyses of a hydrogen liquefaction plant equipped with mixed refrigerant system. Journal of Cleaner Production 2017, 144, 248-259, doi:10.1016/j.jclepro.2017.01.014.

13. Skaugen, G.; Berstad, D.; Wilhelmsen, Ø. Comparing exergy losses and evaluating the potential of catalyst-filled plate-fin and spiral-wound heat exchangers in a large-scale Claude hydrogen liquefaction process. International Journal of Hydrogen Energy 2020, 45, 6663-6679, doi:https://doi.org/10.1016/j.ijhydene.2019.12.076.

14. Cardella, U.; Decker, L.; Sundberg, J.; Klein, H. Process optimization for large-scale hydrogen liquefaction. International Journal of Hydrogen Energy 2017, 42, 12339-12354, doi:10.1016/j.ijhydene.2017.03.167.

15. Yuksel, Y.E.; Ozturk, M.; Dincer, I. Analysis and assessment of a novel hydrogen liquefaction process. International Journal of Hydrogen Energy 2017, 42, 11429-11438.

16. Chang, H.M.; Ryu, K.N.; Baik, J.H. Thermodynamic design of hydrogen liquefaction systems with helium or neon Brayton refrigerator. Cryogenics 2018, 91, 68-76, doi:10.1016/j.cryogenics.2018.02.007.

17. Donaubauer, P.J.; Cardella, U.; Decker, L.; Klein, H. Kinetics and Heat Exchanger Design for Catalytic Ortho-Para Hydrogen Conversion during Liquefaction. Chemical Engineering \& Technology 2019, 42, 669-679, doi:10.1002/ceat.201800345.

18. Wilhelmsen, O.; Berstad, D.; Aasen, A.; Neksa, P.; Skaugen, G. Reducing the exergy destruction in the cryogenic heat exchangers of hydrogen liquefaction processes. International Journal of Hydrogen Energy 2018, 43, 5033-5047, doi:10.1016/j.ijhydene.2018.01.094.

19. Skaugen, G.; Wilhelmsen, O. Comparing the Performance of Plate-Fin and Spiral Wound Heat Exchangers in the Cryogenic Part of the Hydrogen Liquefaction Process. In 15th Cryogenics 2019 Iir International Conference, Chrz, V., Haberstroh, C., Herzog, R., Kaiser, Z., Klier, J., Kralik, T., Lansky, M., Mericka, P., Schustr, P., Srnka, A., et al., Eds.; Refrigeration Science and Technology; Int Inst Refrigeration: Paris, 2019; pp. 318-324.

20. Jackson, S.; Eiksund, O.; Brodal, E. Impact of Ambient Temperature on LNG Liquefaction Process Performance: Energy Efficiency and CO 2 Emissions in Cold Climates. Industrial \& Engineering Chemistry Research 2017, 56, 3388-3398, doi:10.1021/acs.iecr.7b00333.

21. Cardella, U.; Decker, L.; Klein, H. Roadmap to economically viable hydrogen liquefaction. International Journal of Hydrogen Energy 2017, 42, 13329-13338, doi:10.1016/j.ijhydene.2017.01.068.

22. The MathWorks, I. MATLAB, 2018a; Natick, Massachusetts, United States.

23. Span, R.B., R.; Hielscher, S.; Jäger, A.; Mickoleit, E.; Neumann, T.; Pohl, S.; M.; Semrau, B.; Thol, M. TREND. Thermodynamic Reference and Engineering Data 5.0. 2020. 